\title{
Урбанистика, городское развитие, современный опыт Бреста (Беларусь)
}

\author{
Н.Н.Власюк, Брестский горисполком, Брест, Беларусь
}

В статье говорится об урбанистике, современных подходах к развитию и управлению городом на примере опыта города Бреста (Беларусь).

Качество городской среды и экологический подход, скоординированная работа городских служб стали основными приоритетами развития города. Разработка Стратегии пространственного развития-2050, концепции СимбиоСити в увязке с градостроительной документацией дали новый импульс развития областного центра, что является уникальным опытом взаимодействия городской власти, жителей города и бизнеса.

Ключевые слова: урбанистика, стратегия пространственного развития, СимбиоСити, управление городом, качество городской среды, генеральный план.

\section{Urban Studies, Urban Development, Modern Experience of Brest (Belarus)}

N.N.Vlasyuk, Brest City Executive Committee, Brest, Belarus

The article deals with urbanism, modern approaches in the development and management of the city on the example of the experience of Brest (Belarus). The quality of the urban environment and the ecological approach, as well as the coordinated work of city services, have become the main priorities of the city's development. The development of the Spatial Development Strategy-2050, the concept of SymbioSity in conjunction with Urban Planning documentation gave a new impetus to the development of the regional center, a unique experience of interaction between the city government, city residents and business.

Keywords: urbanism, spatial development strategy, Symbiosis, city management, urban environment quality, master plan.

Город - это сложный живой организм взаимодействия различных структур и систем, при этом каждый город, как и каждый человек, уникален и индивидуален. Большинство городов постсоветского пространства активно развивались в индустриальную эпоху. Наши модернистские города как бы «одеты» в одинаковые мундиры, сшитые по меркам строительных норм и правил, застроили типовыми зданиями, но... забыли про тех, для кого строили, про человека - его потребности, его масштаб, душу.

В сегодняшнем глобальном мире не страны, а города конкурируют за людские ресурсы. Какой город лучше, где больше возможностей - там и будут жить и оставлять налоги, туда будут стремиться молодые, энергичные и креативные - будь это IT-шник, фрилансер, музыкант или бизнесмен.

За последнее десятилетие в странах постсоветского пространства стали меняться походы к проектированию городов - от модернистского градостроительства к идеям гуманизации и экологичности городской среды. Развитие города должно зависеть от потребностей жителей.

В современной модели оценки эффективности развития городов Беларуси превалирует количественный подход: эффективность развития измеряется построенными квадратными метрами жилья, километрами дорог и улиц, процентом озеленения. Данные показатели являются маркерами в итоговых республиканских отчетах, где городские власти стараются достичь необходимых результатов: больше город - больше жителей, больше построенных дорог и улиц. Но как в целом это влияет на город и качество жизни городского населения?

Современному городу для качественного развития необходимо иметь собственную пространственную стратегию. Генеральный план важен, но даже он не может удовлетворить имеющиеся запросы жителей. Он в большей степени отвечает на вопросы, сколько и где строить, но не как. Более того, в современном быстроменяющемся мире генеральный план в определённой степени уже сдерживает инвестиционную динамику (например, если заявленная инвесторами или застройщиком функция отличается от утверждённой в градостроительном проекте) из-за сложной процедуры внесения изменений. Генеральный план, являющийся основным документом в сфере градостроительства, предназначен в большей степени для узкого круга специалистов - управленцев, архитекторов и землеустроителей, однако без достаточного социально-экономического обоснования большинство генеральных планов рискуют остаться только на бумаге.

В последнее время в Министерстве архитектуры и строительства Беларуси много говорится о создании комфортной среды в микрорайонах-новостройках. Неоднократно акцентировалось внимание на необходимости:

- создания районов малоэтажной застройки, реализации пилотных проектов по комплексной застройке земельных участков малоэтажными жилыми домами в больших городах;

- развития городов-спутников крупных городов;

- решения задач по озеленению при строительстве новых микрорайонов. В градостроительной политике Республики Беларусь, Государственной схеме комплексной территориальной организации упор делается на сдерживании роста столицы и на развитии столичной агломерации при сохранении на- 
селения малых и средних городов страны. Но как добиться того, чтобы данная схема заработала? Для сохранения жизни в таких городах очень важно определить идентичность населённых мест и, как следствие, их сильные стороны для дальнейшего экономического развития. Двигаться нужно не только сверху-вниз (республиканские программы, планы), но и снизу-вверх, учитывая интересы и перспективы самих

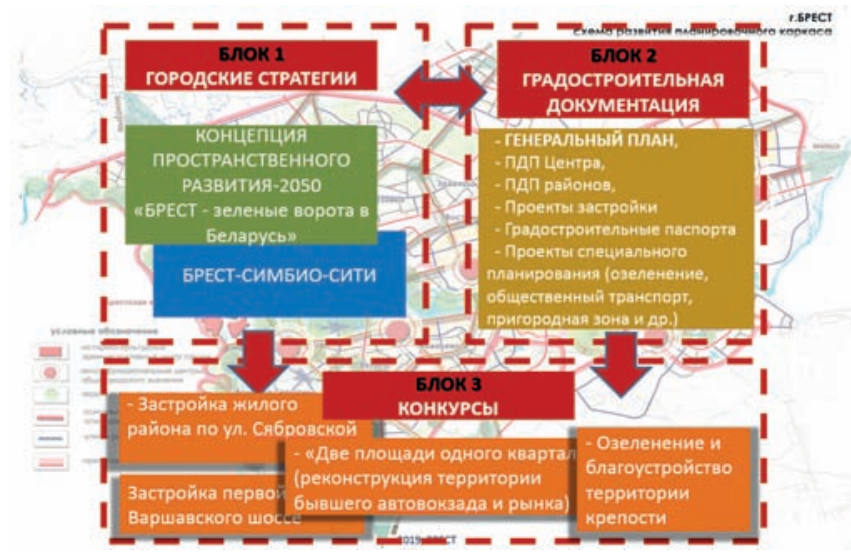

Рис. 1. Брест. Современные тенденции планирования города и застройки

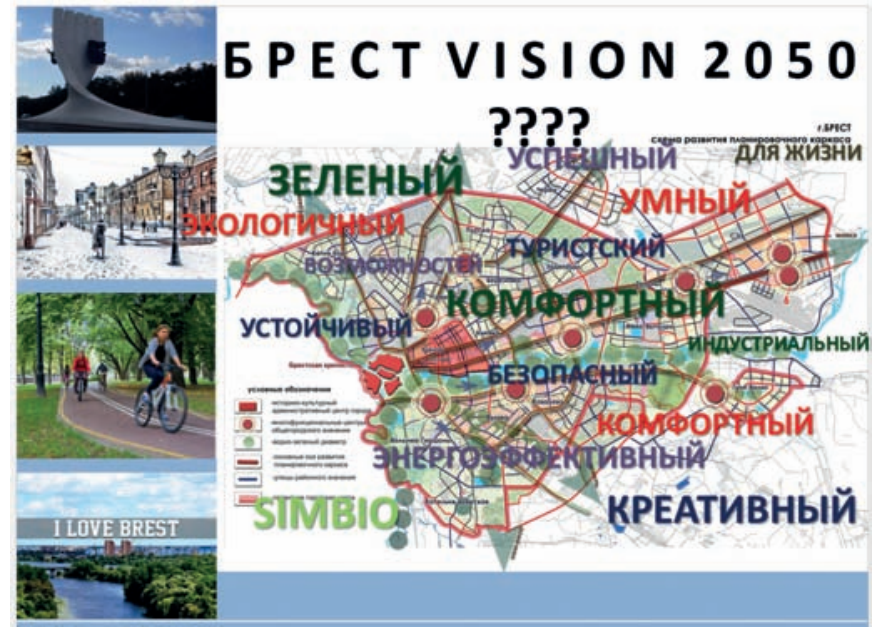

Рис. 2. Брест. Ви́дение

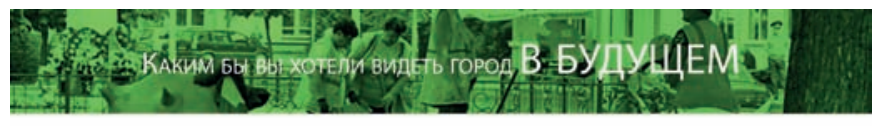

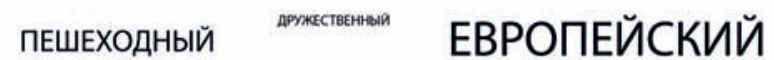
СОВРЕМЕННЫЙ живои ИСТОРИЧЕСКИЙ

ночнои ЗЕЛЁНЫЙ

HАБЕРЕЖНАЯ

ГОСТЕПРИИМНЫЙ РЕчноИ

здОРОвыЙ

БЛАГОУСТРОЕННЫЙ ВЕЛОСИПЕДНЫЙ

ЮЖНАЯ СТОЛИЦА БЕЛАРУСИ

ТУРИСТИЧЕСКИЙ населённых мест и мнения жителей и городской власти. Необходимо дать больше самостоятельности городам для определения политики собственного развития.

К примеру, в Германии или в Италии - большинство жителей не стремятся жить в столице. Не стремятся переехать из Флоренции в Рим, а из Дрездена или Лейпцига в Берлин. Каждый город особенный, уникальный, в каждом своя изюминка, свой бренд, своя стратегия развития, свой бюджет. И сегодня практически нереально, используя административный ресурс, политику развития агломерации с городами-спутниками (а в реальности - опять спальными районами), остановить рост Минска, впрочем, как и Москвы и других столиц СНГ, которые, как магнит, вытягивают людские ресурсы с больших и малых городов. Наши города сегодня болеют, и, как врачи ставящие диагноз и лечащие пациентов, - нам нужны урбанисты-градостроители и урбанисты управленцы, которые, определив проблемы и потенциал городов, смогут выписать соответствующий рецепт и рекомендации для органов управления. По сути для Беларуси это новая область знаний - городское управление. Это отдельная тема разговора - компетенция органов управления, понимание современных процессов развития города, городской политики, взаимодействие городских структур и понимание современного запроса общества, горожан.

Современные требования жителей наших городов, понятие комфортной городской среды поднимают планку для органов власти, принимающих решения, проектировщиков, градостроителей.

Сегодня Управление архитектуры и градостроительства в Бресте в своей деятельности по развитию города и городской застройки опирается на три основных блока: теоретический - городские стратегии и концепции; градостроительная документация; архитектурные конкурсы (рис. 1).

\section{Стратегия пространственного развития}

В 2016 году Управлением архитектуры и градостроительства на базе Технического университета проводится ряд круглых столов на тему: «Стратегия пространственного развития-2050, Видение» (рис. 2), ведётся социологический опрос: «Что Вам нравится в городе, а что не нравится, каким бы Вы хотели видеть город в будущем?» (рис. 3). Инфоцентром горисполкома разработаны анкеты для опроса жителей, вывешены две карты размером 2,5 × 2,5 м с планом целого города и исторического центра. Предлагается возможность обозначить стикерами разных цветов на карте «хорошие» и «плохие» места в городе, по мнению самих жителей, пронумерованные стикеры можно пояснить в отдельном журнале.

Исследование сопровождалось социологическим опросом, работой с международными и местными экспертами, спецИалистами РУП «БЕЛНИИПГРАДОСТРОИТЕЛЬСТВА», инвесторами, общественными организациями и местными органами власти, оценкой сильных и слабых сторон - SWOT(C)-

Рис. 3. Визуализация соцопроса 
анализ. Концепция послужила заданием на проектирование градостроительной документации и в итоге стала отдельным документом.

Стратегия пространственного развития и его структура состоит из видения «БРЕСТ-2050», целевых установок и десяти направлений:

- стратегия компактного города «Большой Брест»;

- стратегия зеленого каркаса, водного диаметра (Центральный городской парк);

- городская идентичность, бренд «Южная столица»;

- стратегия городской мобильности (транспортно-пересадочные узлы);

- стратегия общественных пространств, пешеходные улицы;

- стратегия жилых районов: а) преобразования, обновление сложившихся спальных районов; б) новые районы застройки, соседства, жилой модуль, энергоэффективный модуль;

- стратегия «Исторический центр, крепость, историкокультурные ценности»;

- стратегия «Зоны роста»: технопарк, производственные и IT-кластеры, сфера обслуживания;

- стратегия «Городская застройка, доминанты, силуэт города»;

- стратегия городской среды: уникальный ландшафт, любимые места, универсальный дизайн, экодизайн, концепция рекламы, «город света»;

- стратегия интегрированного города (СимбиоСити): управление городским хозяйством.

Определён перечень первоочередных и долгосрочных проектов, целевые показатели, механизмы реализации и индикаторы эффективности. Определён профиль города, который оценивает восемь типов пространств по различным критериям. Система оценки состоит из ряда индикаторов, отвечающих за определённый тип городского пространства и отображающих степень качества среды по каждому из критериев.

Механизмы реализации. На сегодняшний день при «оптимизации» органов государственного управления, создании системы административных процедур «одно окно» роль органов, курирующих вопросы градостроительного развития, архитектуры и городского дизайна, зачастую сводится к механизму по принятию решений (разрешить или нет). При этом развитие города - сложный процесс, целая наука и даже искусство. И будет ли оно иметь правильную, положительную динамику, в первую очередь зависит от наличия экспертов, команды профессионалов по городскому развитию, занимающихся разработкой проектов, стратегий и их реализацией.

\section{Концепция СимбиоСити}

Параллельно, в соответствии с постановлением Совета министров и Национальным планом действий по развитию зелёной экономики в Беларуси Брест включается в проект «Зелёные города» с разработкой концепции СимбиоСити. Это модель умного, устойчивого городского развития, которая основана на взаимодействии (синергии) семи городских систем: климата, транспорта, архитектуры и ландшафта, управления отходами, водоснабжения и водоотведения, городского управления (рис. 4). В горисполкоме создаётся группа экспертов по направлениям, которые объединены общей экологической целью.

По каждому из семи направлений концепции были определены цели на перспективу - до 2025, 2035 и 2050 годов. При этом международный эксперт запросил большой перечень данных, по которым можно делать сравнительный анализ развития города. Оказалось, что половины таких показателей в нашей статистике просто нет! Мы считаем по-разному количество домохозяйств, обеспеченных интернетом, уровень занятости населения и т.д. Тем не менее методика подсчётов не является непреодолимым препятствием.

Концепция была утверждена городским советом депутатов. Это результат совместной работы белорусских, европейских экспертов-урбанистов и городской власти в рамках проекта ПРООН «Зелёные города». Используемые в модели «СимбиоСити» экологические, энергоэффективные технологии сами по себе и каждая в отдельности специалистам хорошо известны. Синергетический эффект возникает тогда, когда существующие порознь и решающие локально свои проблемы отрасли городского хозяйства начинают решать их сообща. В мире с 90-х годов прошлого века накоплен огромный опыт организации подобных процессов. Так, например, этот опыт доказывает, что можно более эффективно использовать ресурс бытового мусора для генерации энергии и выработки вторсырья, для последующего рециклинга. Город Брест, присоединившийся к Соглашению мэров по климату и энергии в 2015 году, в соответствии с концепцией «Брест: СимбиоСити 2050» планирует достичь снижения уровня выбросов $\mathrm{CO}_{2}$ до 20\% по сравнению с 2010 годом, и реализовать концепцию «Зелёный город». При условии начала реализации этой концепции город получит новые возможности для развития интегрированной устойчивой городской системы, обладающей синергетическими связями между отраслями и основанной на энергоэффективности, умном управлении землепользова-

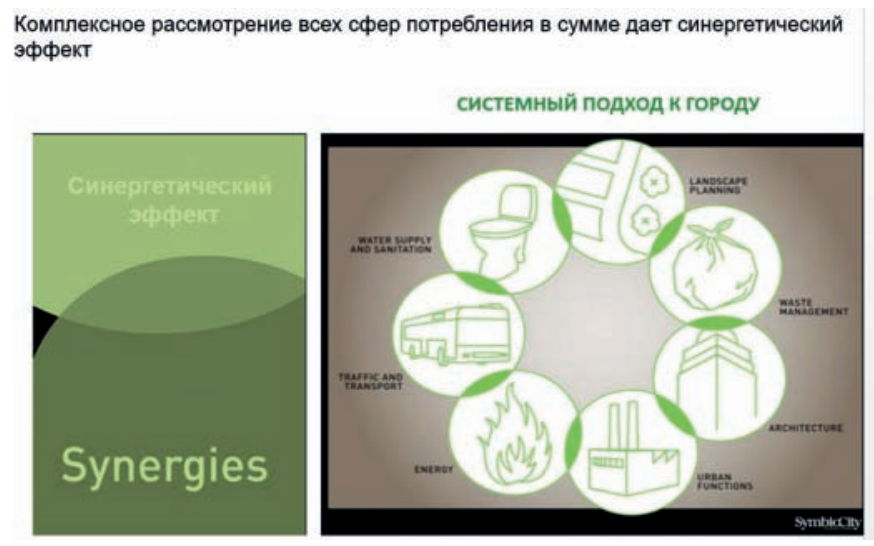

Puс. 4. СимбиоСити. Системный подход к городу 
нием, снижении потребления и возобновляемости ресурсов, удобной и эффективной транспортной системе, росте благосостояния и многогранной культурной идентичности общества. Это позволит создать условия для согласованных действий в рамках нескольких местных городских систем (архитектура и ландшафт; энергия и климат; городская мобильность; отходы; водоснабжение и водоотведение; образование и культура), которые являются основой развития города, в целях адаптации к изменениям климата и получения экономической, социальной и экологической пользы.

«СимбиоСити» - это своего рода программа социальноэкономического развития Бреста, адаптированная к европейским требованиям. Что в свою очередь также позволяет привлекать грантовые средства по программам, которые реализуют ПРООН, Северный инвестиционный банк, Европейский банк развития и другие международные финансовые институты. К примеру, уже на стадии разработки концепции «СимбиоСити» город выиграл грант по интеллектуальной системе светофорного регулирования, что помогает упорядочить транспортную систему, система уже сегодня реализуется.

\section{Разработка градостроительной документации}

В 2017 году УП «БЕЛНИИПГРАДОСТРОИТЕЛЬСТВА» началась разработка Генерального плана города (рис. 5) и Детального

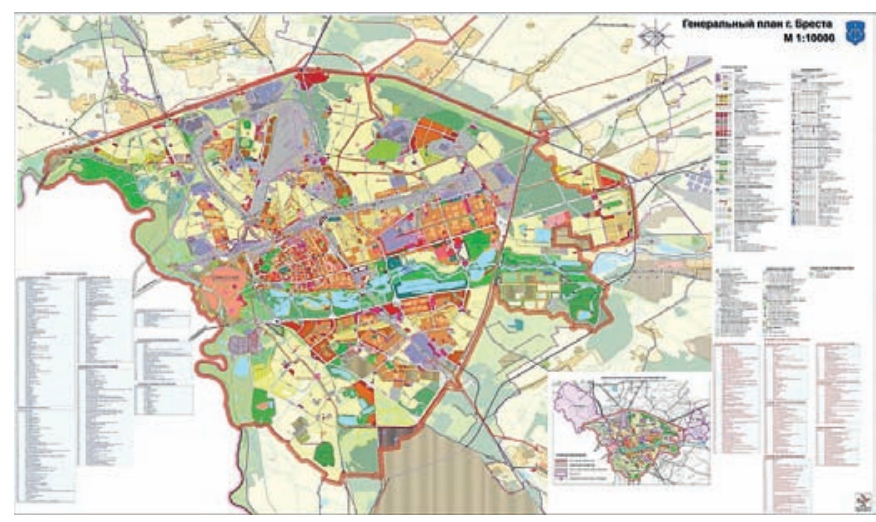

Рис. 5. Брест. Генеральный план. 2019 год

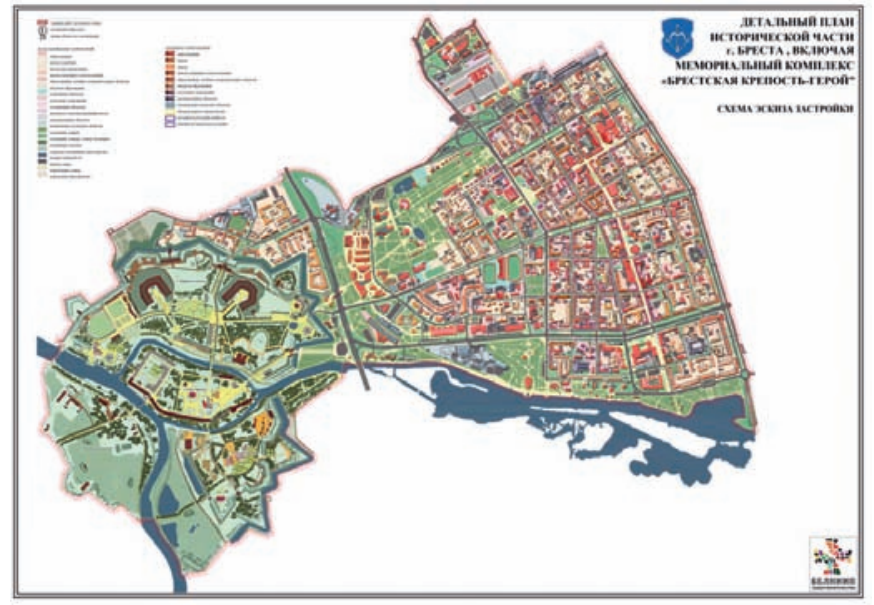

Рис. 6. Брест. Детальный план исторического чентра плана регенерации исторического центра (рис. 6). В задание на проектирование были включены наработки Стратегии пространственного развития-2050 и концепции СимбиоСити. Это по-своему уникальный для Беларуси опыт, где удалось совместить в градостроительной документации, утверждаемой Главой государства и городом, теоретический градостроительный анализ вместе с запросом и пожеланиями жителей города.

В 2018 году на городской сессий депутатов была утверждена концепция СимбиоСити, в 2019 году - Стратегия пространственного развития Брест-2050. В 2019 году утверждены Генеральный план областного центра и детальный план исторического центра города Бреста. Город получил дорожную карту для дальнейшего качественного развития.

Для успешного воплощения стратегии городского развития необходима модернизация существующих процедур и инструментов:

- формирование бюджета города в соответствии с приоритетами Стратегии с применением экспертных оценок при систематизации и ранжировании проектов;

- разработка проектов градостроительного планирования (ПДП, проектов специального планирования, градостроительных паспортов, стратегий) и совершенствование документов городского планирования;

- налаживание диалога с городским сообществом, общественными организациями, вовлечение их в реализацию городских проектов;

- создание структуры - КУП или отдел (агентство реализации городских стратегий) по формулированию, разработке городских проектов, стратегий и их продвижению.

\section{Реализация}

Уже сейчас в Бресте приступили к реализации ряда проектов в соответствии с направлениями утверждённой стратегии. Полным ходом идет реконструкция и благоустройство набережной реки Мухавец. Различные общественные организации, такие как «Время земли», «За вело-Брест», а также жители активно участвуют в озеленении города в рамках реализации бренда «Южная столица». Увеличена общая протяжённость велодорожек.

В ближайшее время планируется создание новой пешеходной улицы Пушкинской. Подведены итоги международного архитектурного конкурса на создание нового общественного пространства «Две площади одного квартала» на месте бывшего автовокзала.

В разы увеличен уровень озеленения города: произведена реконструкция исторического парка «Городской сад», в сложившихся микрорайонах благоустраиваются зелёные зоны (парк Мира, сквер в Южном, сквер по Сальникова-ЮЗМР-3) и закладываются новые парки и скверы (парк 1000-летия, сквер по улице Волгоградской, сквер Брестской Библии, сквер Пушкина, сквер в районе Партизанского проспекта).

По итогам работы за 2019 год город получил первое место по благоустройству среди больших и крупных городов Беларуси. 
Сдан в эксплуатацию новый автовокзал. Он расположен рядом с железнодорожным как часть крупного транспортнопересадочного узла (реализация стратегии общественного транспорта). Здесь сосредоточены пригородный вокзал, конечная станция троллейбусных маршрутов, в ближайшее время планируется устройство конечной станции городских автобусных маршрутов.

Ведётся застройка новой транспортной магистрали: Варшавское шоссе-гостиница Хилтон, бизнес-центр. Особое внимание уделяется силуэту застройки улицы и новым доминатам (Интенданский городок, квартал ГОБК).

Идёт работа по изменению принципов застройки жилых районов: проведён конкурс на концепцию застройки кварталов жилого района с реконструкцией форта № 4 по ул. Сябровской (рис. 12), проекты детального планирования ЮЗМР-1, Южный, Волынка-Гершоны (Брестская Венеция); все новые районы имеют узнаваемый дизайн-код, современный графический дизайн, по которому легко идентифицировать район и ориентироваться в городе. В Бресте активными темпами реконструируется существующий технопарк, размещённый в бывшей промзоне, объявлен конкурс на концепцию технопарка «СмартСити». Подписан инвестдоговор на строительство первой очереди современного IT-кластера в районе технического университета.

В рамках взаимодействия Управления архитектуры и КУП Центр архитектуры разработан градостроительный кадастр города, ведётся дежурный план. Разрабатываются проекты специального планирования: Схема озеленённых территорий общего пользования, Схема пригородной зоны г. Бреста, Схема развития общественного транспорта. Брест обретает новые черты современного, обустроенного, комфортного зелёного города.

Реализация Стратегии пространственного развития Бреста планируется в проектном формате различных масштабов: на краткосрочную и долгосрочную перспективы. Проектно-ориентированный подход обеспечивает гибкость и динамичность управления процессами городского развития, а также обеспечивает смену отраслевого подхода управления на комплексно ориентированное проектное городское управление (обеспечивает взаимодействие различных сторон в рамках достижения целевых показателей конкретных проектов). Каждый из проектов предполагает реализацию набора мероприятий как нематериального характера (организационные, административные, событийные и пр.), так и материального (строительство капитальных или временных объектов, развитие инфраструктуры и пр.). Проекты имеют достижимые цели и сроки реализации.

В соответствии с городскими приоритетами определяется доступность ресурсов для реализации проектов (городской бюджет, программы областного и республиканского уровней, частные инвестиции), формируется дорожная карта реализации стратегии. Документ стратегического планирования помогает определить основные векторы городского развития, заложить ключевые направления пространственного развития.

Таким образом, дополнение градостроительной документации Стратегией пространственного развития города позволяет:

- определить приоритеты и векторы пространственного развития города и приоритеты развития экономики;

- сделать акцент на качественном улучшении городской среды. Управлять и сопровождать реализацию стратегии предлагается специально созданному отделу в исполкоме либо КУП «Агентство по городскому развитию». Реализация стратегии позволит сделать наши города более привлекательными и уютными для жизни.

Власюк Николай Николаевич (Брест, Республика Беларусь). Кандидат архитектуры, доцент. Главный архитектор города Бреста, начальник управления архитектуры и градостроительства Брестского горисполкома (Беларусь, Брест, ул. Энгельса, 3. Брестский горисполком). Эл. почта: ulasiuk@list.ru.

Vlasyuk Nikolay N. (Brest, Republic of Belarus). Candidate of Architecture, Associate Professor. Chief Architect of the City of Brest, Head of the Department of Architecture and Urban Planning at the Brest City Executive Committee (3 Engels St., Brest, Belarus, Republic of Belarus, 224005. Brest City Executive Committee). E-mail: ulasiuk@list.ru. 